University of Nebraska - Lincoln

DigitalCommons@University of Nebraska - Lincoln

8-1-1987

\title{
Chemically Driven Convection in a Porous Medium.
}

\author{
Hendrik J. Viljoen \\ University of Nebraska-Lincoln, hviljoen1@unl.edu \\ $\checkmark$ Hlavacek \\ Department of Chemical Engineering, State University of New York, Buffalo, NY 14260
}

Follow this and additional works at: https://digitalcommons.unl.edu/chemengchemreact

Part of the Chemical Engineering Commons

Viljoen, Hendrik J. and Hlavacek, V, "Chemically Driven Convection in a Porous Medium." (1987). Papers in Chemical Reactions. 1.

https://digitalcommons.unl.edu/chemengchemreact/1

This Article is brought to you for free and open access by the Chemical and Biomolecular Engineering Research and Publications at DigitalCommons@University of Nebraska - Lincoln. It has been accepted for inclusion in Papers in Chemical Reactions by an authorized administrator of DigitalCommons@University of Nebraska - Lincoln. 


\title{
Chemically Driven Convection in a Porous Medium.
}

\author{
H. Viljoen And V. Hlavacek. August 1987, Vol. 33, No. 8 AlChE Journal. \\ (C) American Institute of Chemical Engineers.
}

This paper is focused on the analysis of interaction of free convection and exothermic chemical reaction. As a consequence of the chemical reaction, free convection effects can result. It is difficult to perform an analytical bifurcation analysis of the full nonlinear governing equations; however, Fourier expansion combined with a Galerkin approximation results in a small s e t of ordinary nonlinear differential equations (initial value problem) that are amenable to analysis. Conditions for branching of the solution can be determined in an analytical way. A continuation algorithm makes it possible to calculate the branches of stability. The results of the approximate analysis are supported by the numerical integration of the full governing nonlinear equations.

Introduction

Natural convection may influence the course of an exothermic chemical reaction in a critical way, Examples of the interaction of chemical reaction and free convection occur in tubular laboratory reactors, chemical vapor deposition systems, oxidation of solid materials in large containers, synthesis of ceramic materials by a self-propagating reaction and others.

There is little information on the interaction of free convection and chemical reaction in the literature. Merzhanov and Shtessel (1973) investigated the effect of free convection on the explosive characteristics of liquid explosives. Shtessel et al. (1971) solved numerically thermal explosion equations in combination with equations of fluid motion. Since they used only one type of perturbation, only one type of convection solution was found. Kordylewski and Krajewski (1984) solved a similar problem in a cylindrical cavity. For certain values of the parameters they found oscillatory behavior. In order to make the problem more tractable, we introduce two essential approximations. First, 


\section{Chemically Driven Convection in a Porous Medium.}

H. Viljoen And V. Hlavacek. August 1987, Vol. 33, No. 8 AIChE Journal.

(C) American Institute of Chemical Engineers.

we adopt the Bousinesq approximation. Any change in density is assumed negligible except in the external force term of the Navier- Stokes equations. Second. We will consider flow through a porous medium and hence assume that the Darey approximation is valid. We will consider a two-dimensional cavity with insulated side walls and bottom. The top will be kept at a fixed temperature and a zero-order reaction will drive the convection. The model that describes this situation will be referred to as Models and Their Bifurcation Behavior We consider a zero-order exothermic reaction in a rectangular cavity of width-to-height ratio of a. In Figure 1, we state the problem schematically. The continuity, momentum, and energy conservation equations can be written in nondimensional form: the original system. We will simplify the original system by approximating the dependent variables with a truncated Fourier series. We will show that the resulting initial-value problem has preserved most of the features of the original system. In the text we will refer to the Fourier-approximated equation: as the simplified system.

\section{Models and Their Bifurcation Behavior}

We consider a zero-order exothermic reaction in a rectangular cavity of width-to-height ratio of a. In Figure 1, we state the problem schematically. The continuity, momentum, and energy conservation equations can be written in non-dimensional form: 
Chemically Driven Convection in a Porous Medium.

H. Viljoen And V. Hlavacek. August 1987, Vol. 33, No. 8 AIChE Journal.

(c) American Institute of Chemical Engineers.

$$
\begin{gathered}
\nabla \cdot \omega-0 \\
\frac{1}{\operatorname{Pr}}\left(\frac{\partial u}{\partial t}+\frac{1}{t} u \cdot \nabla u\right)--\nabla P-\operatorname{Ra\theta } \hat{z}-u
\end{gathered}
$$

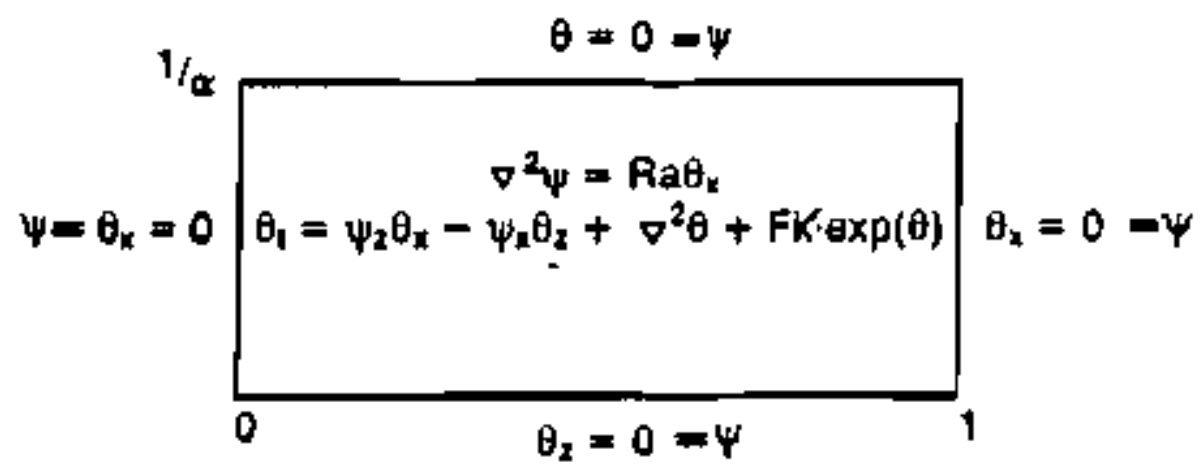

Flgure 1. Model equatlons and boundary conditlons. 
Chemically Driven Convection in a Porous Medium.

H. Viljoen And V. Hlavacek. August 1987, Vol. 33, No. 8 AIChE Journal.

(C) American Institute of Chemical Engineers.

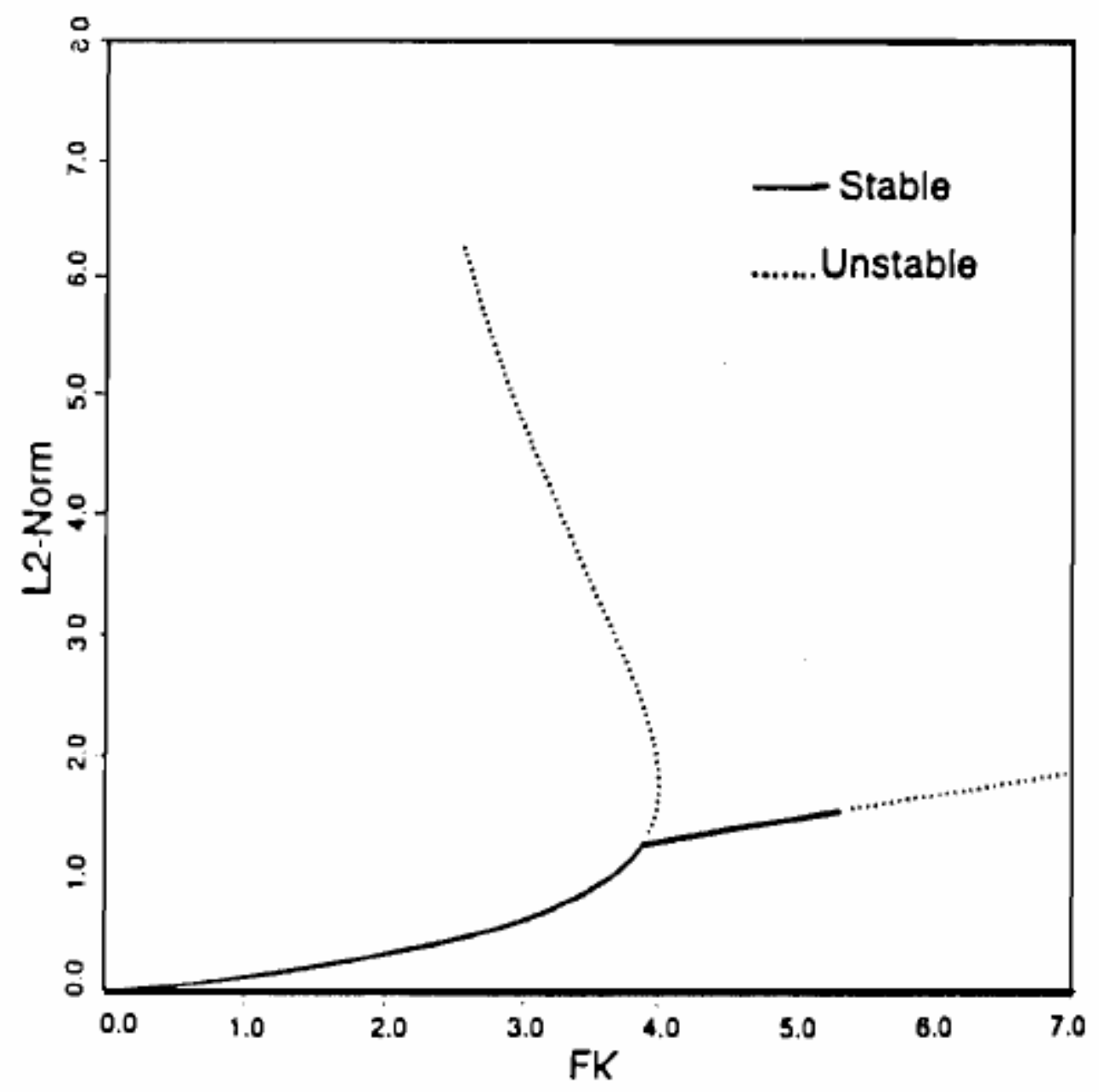

Figure 2. Bifurcation dlagram of Eqs. 16 and 17 for $R a-$ 30.

$$
\frac{\partial \theta}{\partial r}+u \cdot \nabla \theta=\nabla^{2} \theta+F K \exp (\theta)
$$




\section{Chemically Driven Convection in a Porous Medium.}

H. Viljoen And V. Hlavacek. August 1987, Vol. 33, No. 8 AlChE Journal.

(C) American Institute of Chemical Engineers.

Where $\boldsymbol{u} \boldsymbol{P}$, and $\boldsymbol{O}$ respectively denote a dimensionless velocity, pressure, and temperature. $\boldsymbol{P r}$ is the Prandtl number as defined - a porous medium, $\mathbf{R a}$ is the thermal Rayleigh number, and $\boldsymbol{r} \boldsymbol{K}$ is the Frank-Kamenetskii parameter defined in the Notation. Since we only consider two space dimensions, we can write:

Eqs. 1-3 in terms of a stream function. Let:

$$
\left(-\frac{\partial \psi}{\partial z}, \frac{\partial \psi}{\partial x}\right)-\left(u_{x}, u_{t}\right)
$$

where the subscripta denote the appropriate component. Substituting Eq. 4 into Eqs. 1-3 gives:

$$
\begin{gathered}
\frac{1}{\operatorname{Pr}} \frac{\partial}{\partial f}\left(\nabla^{2} \psi\right)--\nabla^{2} \psi+R a \frac{\partial \theta}{\partial x} \\
\frac{\partial \theta}{\partial t}=\nabla^{2} \theta-\frac{\partial \psi}{\partial x} \frac{\partial \theta}{\partial z}+\frac{\partial \psi}{\partial z} \frac{\partial \theta}{\partial x}+\text { FK } \exp (\theta)
\end{gathered}
$$

The Prandtl number assumes large values in a great many practical situations, and hence Eqs. 5 and 6 reduce to

$$
\nabla^{2} \psi=R a \frac{\partial \theta}{\partial x}
$$

$$
\frac{\partial \theta}{\partial t}=\nabla^{2} \theta-\frac{\partial \psi}{\partial x} \frac{\partial \theta}{\partial z}+\frac{\partial \psi}{\partial z} \frac{\partial \theta}{\partial x}+\mathrm{FK} \exp (\theta)
$$




\section{Chemically Driven Convection in a Porous Medium.}

H. Viljoen And V. Hlavacek. August 1987, Vol. 33, No. 8 AlChE Journal.

(C) American Institute of Chemical Engineers.

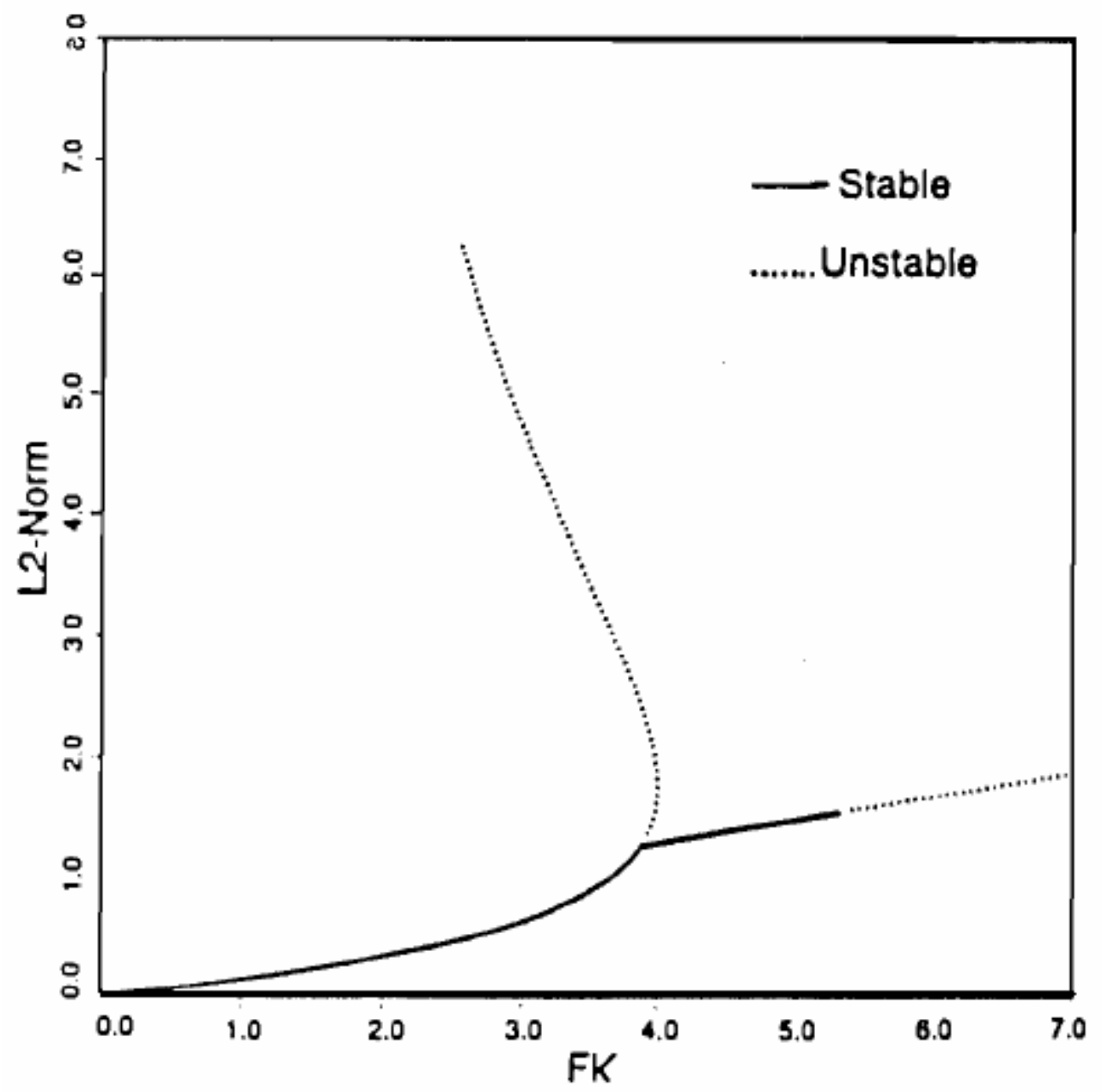

Figure 2. Bifurcation diagram of Eqs. 16 and 17 for $R a 30$.

In the rest of this paper we will refer to Eqs. 7 and 8 as the original system. These equations are supplemented by the boundary conditions shown in Figure 1.

Under conditions of insufficient heat removal, a thermal explosion occurs. Heat removal is facilitated by conduction and convection. If convection is neglected, Eqs. 7 and 8 decouple and a steady state solution of Eq. 8 is only possible for $F K<F K$, where $F K$, is the critical value; e.g... FK, - 0,878 if a - 1 (Buckmaster and Ludford, 1983). 


\section{Chemically Driven Convection in a Porous Medium.}

H. Viljoen And V. Hlavacek. August 1987, Vol. 33, No. 8 AIChE Journal.

(C) American Institute of Chemical Engineers.

Convection stabilizes the reaction to some extent, and steady state solutions of Eqs. 7 and 8 exist for $F K>F K$, at the onset of convection, one can consider 0 as a solution of the conduction problem with convection superimposed on it. The stream function and tem-

$$
\begin{aligned}
& \psi-\sum_{i=1}^{-} \sum_{j=1}^{-} A_{i j}(t) \sin \pi i x \sin \pi \alpha j z \\
& \theta-\cos \left(\frac{\pi \alpha}{2} \tau\right), \sum_{r=0}^{-} D_{k}(t) \cos \pi k x
\end{aligned}
$$

perature can now be approximated by:

The first term of Eq. 10 is purely an approximation of the Steady-state conduction solution and one could have considered here the exact solution given by Buckmaster and Ludford (1983). Note that the conduction solution depends only on $z$.

The higher terms contain h e lateral effects of convection. Substituting Eqs. 9 and 10 into Eqs. 7 and 8, truncating after one and two terms, respectively, and integrating the product of the residual and its approximation functions, one has a Galerkin approximation of Eqs. 7 and 8. For $\alpha$ one gets the following:

$$
\begin{gathered}
0=-A_{11}+\frac{8}{15 \pi^{2}} R a D_{1} \\
\frac{d}{d t} D_{0}=-\pi^{2} D_{0}-\frac{\pi^{2} A_{11} D_{1}}{4} \\
+4 F K\left(\frac{1}{\pi}+\frac{D_{0}}{4}+\frac{D_{0}^{2}}{3 \pi}+\frac{D_{1}^{1}}{6 \pi}\right) \\
\frac{d}{d I} D_{1}=-2 \pi^{2} D_{1}+\frac{\frac{\pi}{2} A_{11} D_{0}}{2}+8 F K\left(\frac{D_{1}}{8}+\frac{D_{0} D_{1}}{3 \pi}\right)
\end{gathered}
$$




\section{Chemically Driven Convection in a Porous Medium.}

H. Viljoen And V. Hlavacek. August 1987, Vol. 33, No. 8 AlChE Journal.

(C) American Institute of Chemical Engineers.

Later we will use two and three terms, respectively, to approximate I) and 8. But in both cases, we will refer to the Galerkin approximation as the simplified system. Let w first consider the conduction behavior of Eqs. 11-13 alone. Now these equations take the form:

$$
\pi^{2} D_{0}-4 F K\left[\frac{1}{x}+\frac{D_{0}}{4}+\frac{D_{0}^{2}}{3 \pi}\right]
$$

and $A_{19}-D_{1}-0$. Equalion 14 bas two solutions for

$$
0<F K<\pi^{2} /[1+8 /(x \sqrt{3})]
$$

with the result $F K=3.995$, which compares reasonably with the analytical value of $F K_{r}=3.512$.

If convection is considered, Eqs. 11-13 can be written as:

$$
\begin{array}{r}
\frac{d}{d t} D_{0}=-\pi^{2} D_{0}-\frac{2 R a D_{1}^{2}}{15}+4 F K\left(\frac{1}{\pi}+\frac{D_{0}}{4}+\frac{D_{0}^{2}}{3 \pi}+\frac{D_{1}^{2}}{6 \pi}\right) \\
\frac{d}{d t} D_{1}=-2 \pi D_{1}+\frac{4 R a D_{0} D_{1}}{15}+8 F K\left(\frac{D_{1}}{8}+\frac{D_{0} D_{1}}{3 \pi}\right)
\end{array}
$$

In Figure 2, a complete bifurcation diagram of Eqs. 16 and 17 is shown. One can immediately recognize the conduction branch. We have chosen a fixed value of $\mathrm{Ra}-30$ and used FK as the variable parameter. Branching of a simple bifurcation type (Keller, 1977) occurs at $F K-3.8757$. At this bifurcation point, two branches emanate and they have solutions (D, 


\section{Chemically Driven Convection in a Porous Medium.}

H. Viljoen And V. Hlavacek. August 1987, Vol. 33, No. 8 AIChE Journal.

(C) American Institute of Chemical Engineers.

$D$, ) and (Do; -D,), respectively. Since we use the Euclidean norm in Figure 2, these two branches coincide in the figure. The two solutions can be interpreted as asymmetrical solutions with hot spots in the lower left and lower right corners of the cavity with clockwise and counterclockwise rotation of each vortex, respectively. The limit point on the conduction branch occurs at $F K-3.995$, see Eq. 15. The convection branch is stable, but at $F K-5.201$ 1 a Hopf bifurcation point is found. Exchange of stability occurs at this point and the convection solution is not stable anymore. We have thus reached the point where convection can no longer stabilize the chemical reaction. One expects that a thermal explosion will occur beyond this point, and the program we have used to compute the bifurcation diagram was unable to find any other solution emanating from the Hopf point. A natural extension of Eqs. $11-13$ for a - 2 is:

Substituting Eqs. 18 and 19 into Eqs. 7 and 8, the resulting Galerkin approximation is;

$$
\begin{gathered}
0--A_{11}+\frac{8}{15 \pi^{2}} R a D_{1} \\
0=-A_{12}+\frac{2}{3 \pi^{2}} R a D_{2} \\
\frac{d D_{0}}{d t}=-\pi^{2} D_{0}-\frac{\pi^{2}}{4} A_{11} D_{1}-\frac{\pi^{2}}{2} A_{12} D_{2}+4 F K \cdot\left(\frac{1}{\pi}+\frac{D_{0}}{4}+\frac{D_{0}^{2}}{3 \pi}+\frac{D_{1}^{2}}{6 \pi}+\frac{D_{2}^{2}}{6 \pi}\right) \\
\frac{d D_{1}}{d t}=-2 \pi^{2} D_{1}+\frac{\pi^{2}}{2} A_{11} D_{0}-\frac{3 \pi^{2}}{4} A_{11} D_{2}+8 F K \cdot\left(\frac{D_{1}}{8}+\frac{D_{0} D_{1}}{3 \pi}+\frac{D_{1} D_{2}}{6 \pi}\right) \\
\frac{d D_{2}}{d t}=-5 \pi^{2} D_{2}+\pi^{2} A_{13} D_{0}+8 F K\left(\frac{D_{2}}{8}+\frac{D_{0} D_{2}}{3 \pi}\right)
\end{gathered}
$$




\section{Chemically Driven Convection in a Porous Medium.}

H. Viljoen And V. Hlavacek. August 1987, Vol. 33, No. 8 AlChE Journal.

(C) American Institute of Chemical Engineers.

\section{$\psi=A_{41}(t) \sin 2 \pi z \sin \pi x+A_{12}(t) \sin 2 \pi z \sin 2 \pi x(18)$ \\ $\theta=D_{0}(t) \cos \pi+D_{1}(t) \cos \pi z \cos \pi x+D_{1}(t) \cos \pi z \cos 2 \pi x$}
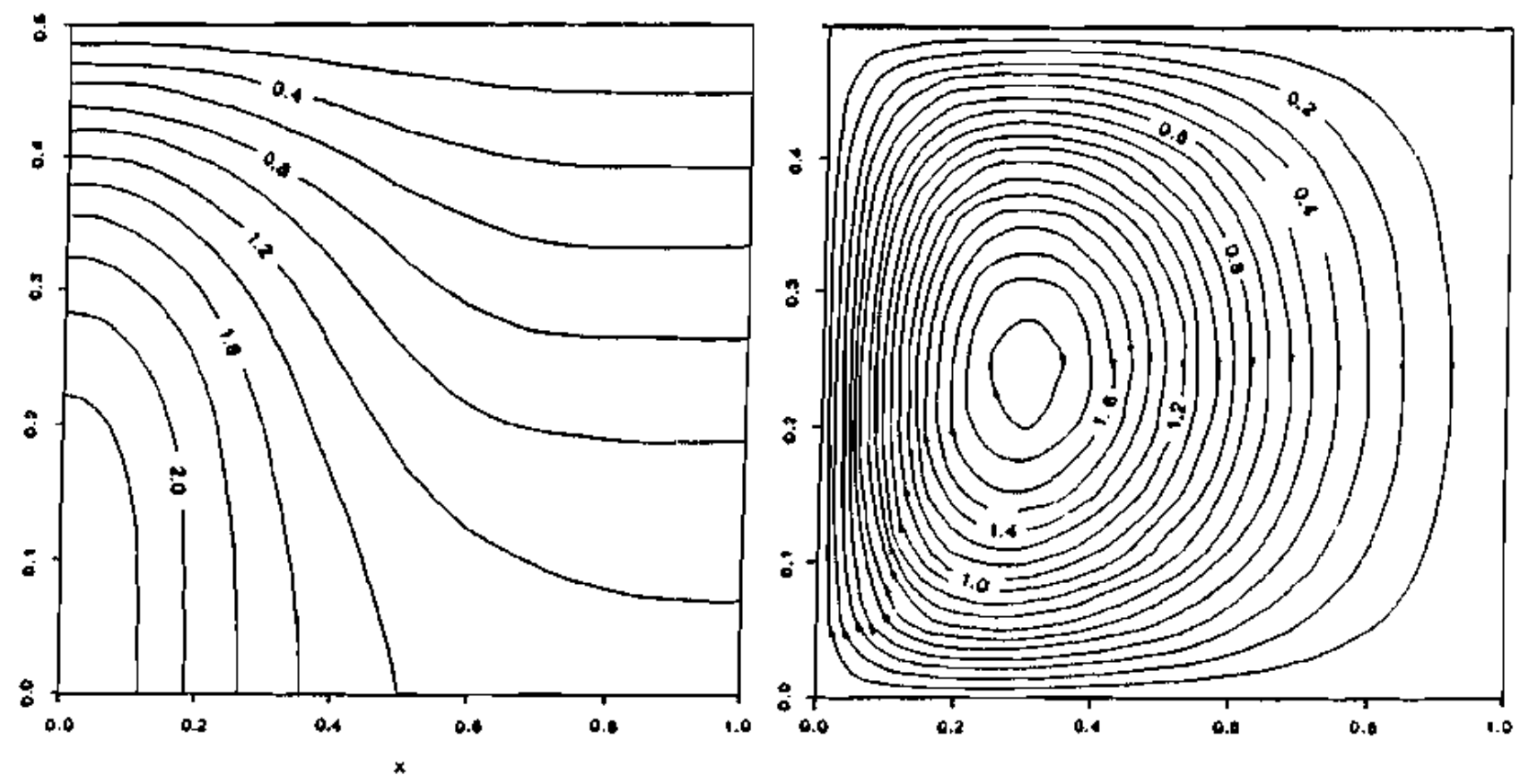

Floute 5 . leotherme and stream function valueg for $F K / F K_{*}-1.281$ and $A a-50$.

In this approximation the convection contribution of the temperature solution consists of two terms, and we will be able to follow the interaction between the two flow patterns. In Figure 3, the bifurcation diagram of Eqs. 20-24 is shown for Ro - 50. Branch 1 is the conduction solution. The first convection branches (branch 2) emanate from the conduction solution at FK - 3.6359 in a way analogous to Eqs. 16 and 17. The same exchange of stability to thermal explosion, as in Figure 2, occurs at $F K-6.061$. A second pair of unstable convection branches (branch 3 ) emanate from the conduction solution at $F K-3.867$. These solutions are of the type $\left(D, ; 0 ;{ }^{*} D,\right)$ and they can be interpreted as two-vortex solutions with two hot spots and one hot spot, respectively. Branch 4 denotes a solution where $D, D$, and $D$, are nonzero. In Figure 4, we present the solutions qualitatively. A further bifurcation point is 


\section{Chemically Driven Convection in a Porous Medium.}

H. Viljoen And V. Hlavacek. August 1987, Vol. 33, No. 8 AIChE Journal.

(C) American Institute of Chemical Engineers.

found on the $(D, ; 0 ; D$,$) branch at F K-4.2671$, and this branch is now stable until a Hopf point at $F K-4.9217$. The tertiary branch that emanates from $(D, ; 0 ;-D$,$) at F K-4.2671$ is also unstable on the interval $4.2671<F K<7$. The crossing of the first branches (D,; +Dl; $0)$ and second branches $(D, ; 0 ;+D$,$) at F K-6$ is purely coincidental and a result of the norm we have chosen. At this crossing point, the solutions are $(0.746 ;+1.0679 ; 0)$ and $(1.1278$; $0.0 ;+0.65)$.

Numerical Verification

To check the validity of the diagrams of Figures 2 and 3 we have integrated the original system at certain points on the bifurcation diagrams. Since the simplified system gives a different value for $F K$, we will compare results between the original and the simplified systems on a basis of FKIFK,. For our numerical investigation we will thus use $F K$ - FK,, @,, $F K$, / FK: where $F K$, denotes the critical value for the original system and $F K$ : is the critical value for the simplified system. We have used an explicit finite-dilference method and time steps have varied between IX 10-' and 5 X 10-'. Poisson's equation was solved by the method of successive over relaxation. We will use the following notation to indicate the type of perturbation and steady-state solution:

1. $>$ asymmetrical, e.g., initial heating in lower left wrner

2. $\triangle \Delta$ symnetrical double hot spot

3. $\triangle$ symmetrical single hot spot

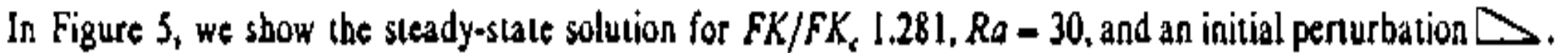
Bolb solutions verify the predictions made by the bifurcation diagram of Figure 2. We have also integra ted the original system at $F K / F K_{\text {t }}$ 


\section{Chemically Driven Convection in a Porous Medium.}

H. Viljoen And V. Hlavacek. August 1987, Vol. 33, No. 8 AIChE Journal.

(c) American Institute of Chemical Engineers.
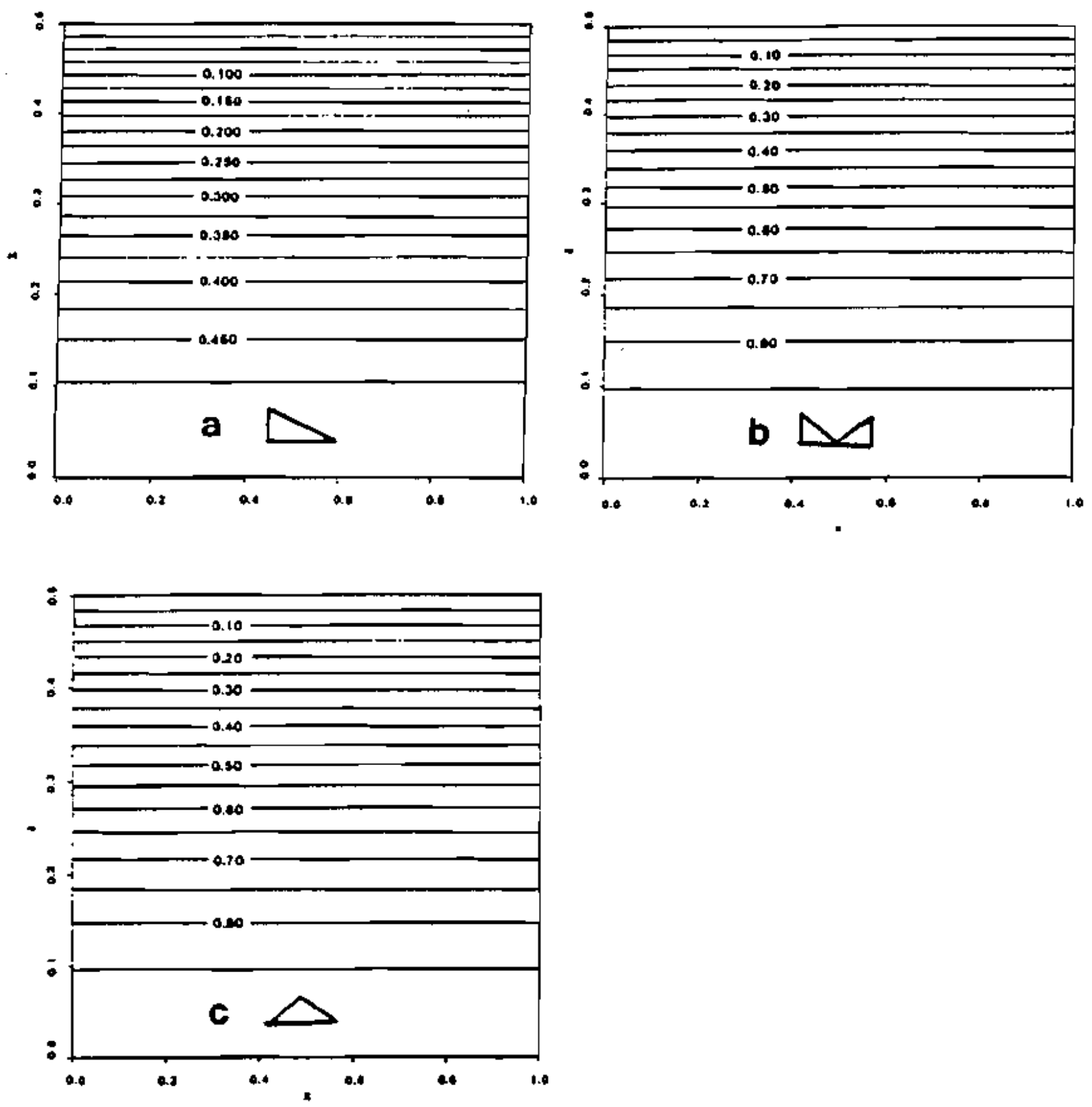

FIgure 6. Steady state solutione for different perturbetione. 


\section{Chemically Driven Convection in a Porous Medium.}

H. Viljoen And V. Hlavacek. August 1987, Vol. 33, No. 8 AlChE Journal.

(C) American Institute of Chemical Engineers.
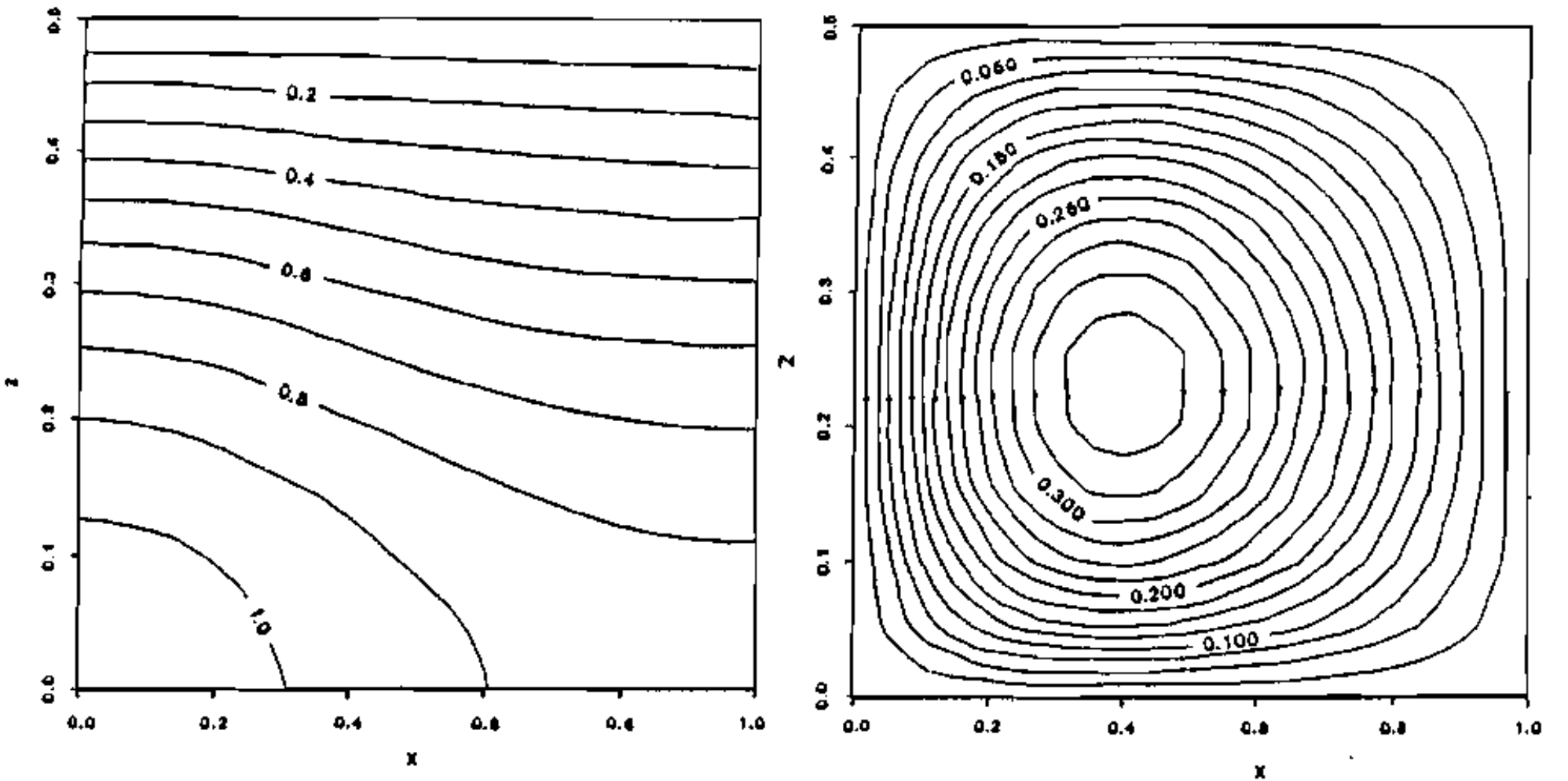

Figure 7. leotherme and atream function values tor $F K / F K_{c}-1.0$ and $A s-50$. 


\section{Chemically Driven Convection in a Porous Medium.}

H. Viljoen And V. Hlavacek. August 1987, Vol. 33, No. 8 AIChE Journal.

(C) American Institute of Chemical Engineers.
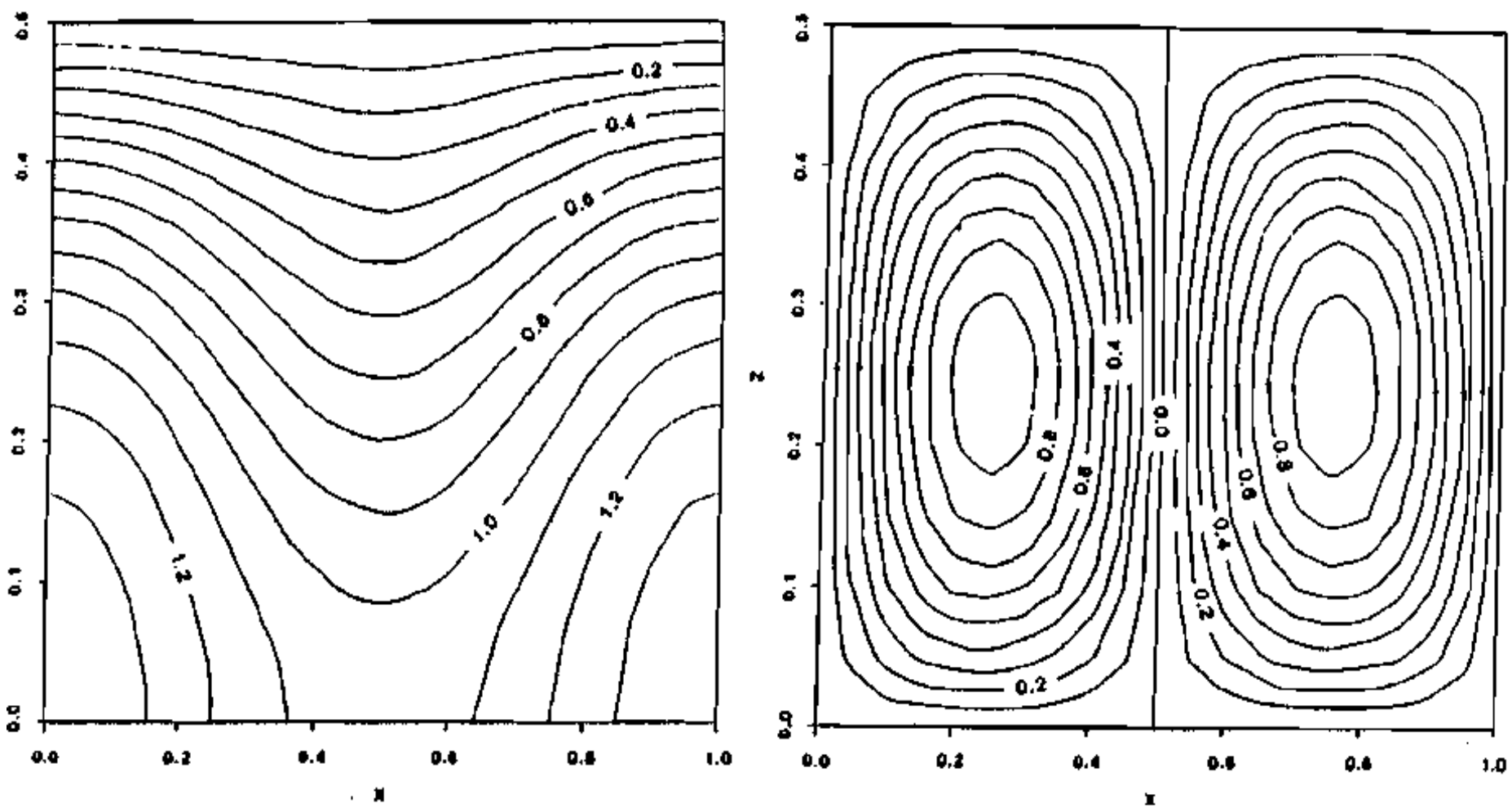

Flgure 8. Isotherme and etream function values tor $F K / F K_{d}=1.189$ and $A s-50$. 


\section{Chemically Driven Convection in a Porous Medium.}

H. Viljoen And V. Hlavacek. August 1987, Vol. 33, No. 8 AIChE Journal.

(C) American Institute of Chemical Engineers.
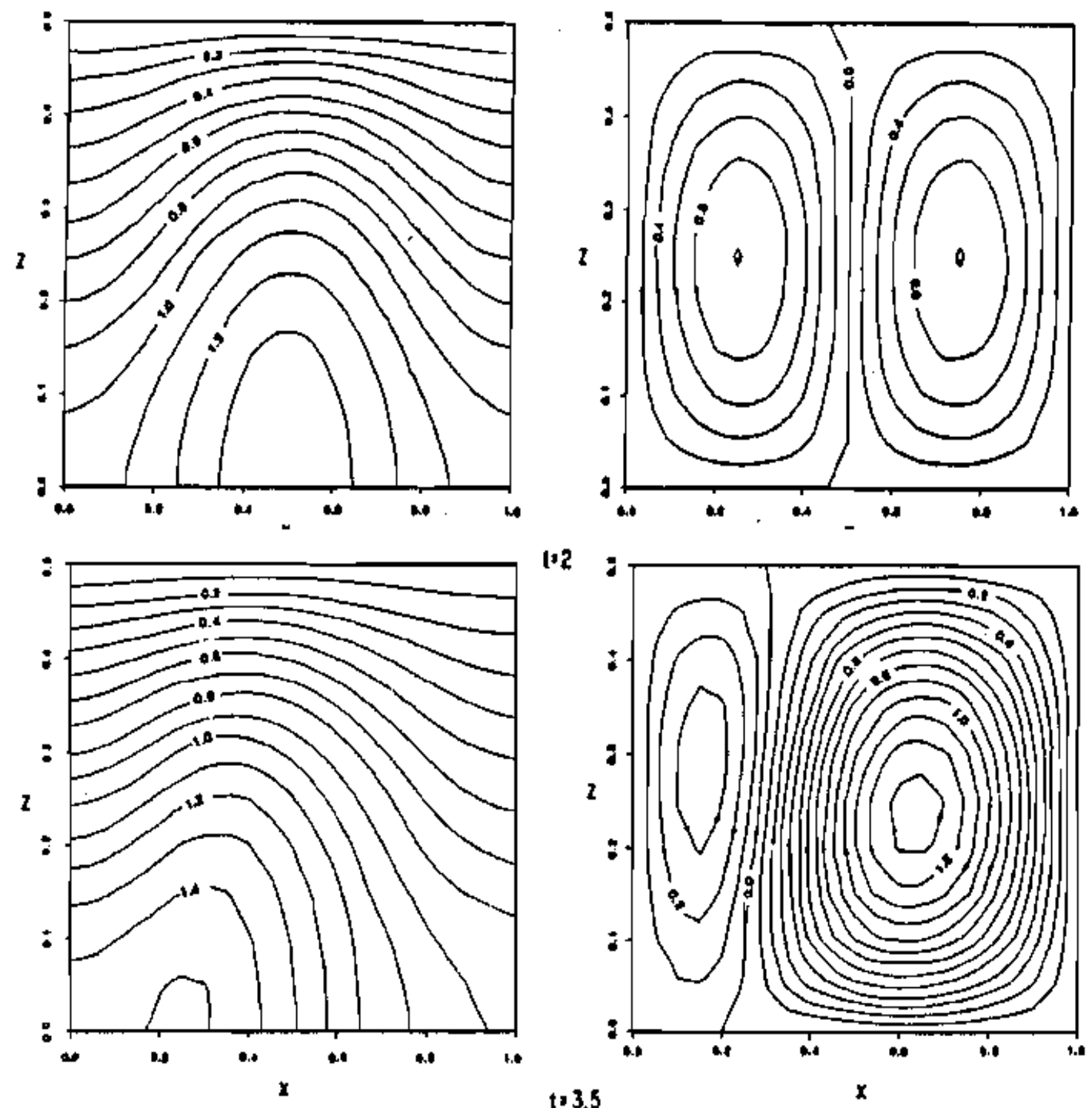

Flgure 9a. Ieotharme and atream functlon valuas for $F K / F K .-1.189$ and $R a-60: t-2$ and 3.5 . 


\section{Chemically Driven Convection in a Porous Medium.}

H. Viljoen And V. Hlavacek. August 1987, Vol. 33, No. 8 AlChE Journal.

(C) American Institute of Chemical Engineers.
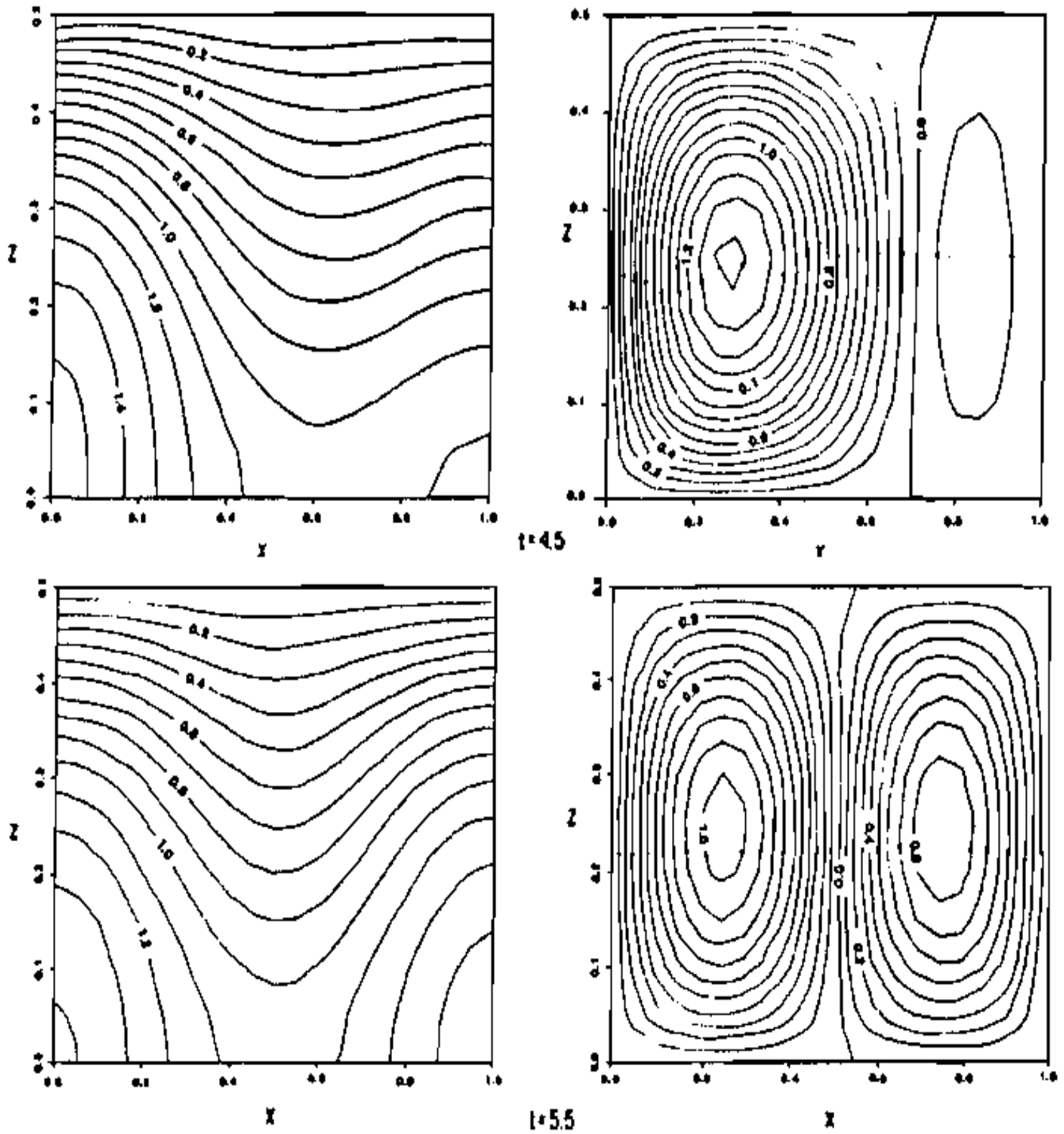

Flgure 9b. Isotherms and otream function valuos for $F K / F K,-1,189$ and $A s-80: t-4.5$ and 8.8 . 
Chemically Driven Convection in a Porous Medium.

H. Viljoen And V. Hlavacek. August 1987, Vol. 33, No. 8 AIChE Journal.

(C) American Institute of Chemical Engineers.

Tuble 1. Parameters and Perturbations for Fig. 6-9 Solutions, Ra $-\mathbf{5 0}$

\begin{tabular}{|c|c|c|c|c|}
\hline \multirow{2}{*}{$\begin{array}{c}\text { Figure } \\
\text { No. }\end{array}$} & \multirow[b]{2}{*}{$\boldsymbol{F} \boldsymbol{K}$} & \multirow[b]{2}{*}{ Perturbation } & \multicolumn{2}{|c|}{ Stiable Solution } \\
\hline & & & Origina] & Simplified \\
\hline 64 & 2.6373 & & Conduction & Conduction \\
\hline $6 b$ & 3.428 & $\angle$ & Conduction & Conduction \\
\hline $6 c$ & 3.428 & $\Delta \Delta$ & Conduction & Conduction \\
\hline 7 & 3.512 & & 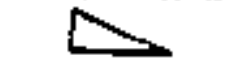 & 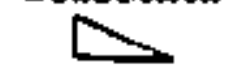 \\
\hline 8 & 4.1757 & $\Delta$ & $\Delta$ & $\Delta$ \\
\hline 9 & 4.1757 & & $\Delta \Delta$ & or $\Delta$ \\
\hline
\end{tabular}

The method of analysis by means of a truncated Fourier series seems to retain the most important properties of the original sys. tem, and the bifureation and stability behavior are correctly predicted by the simplified system. This is a remarkable result especially in light of the fact that Eqs. 1-3 are not very tractable.

\section{Acknowledgment}

Part of this work was supported by National Science Foundalion Grant No. CPE 83-10827, which is gratefully acknowledged. 


\section{Chemically Driven Convection in a Porous Medium.}

H. Viljoen And V. Hlavacek. August 1987, Vol. 33, No. 8 AlChE Journal.

(C) American Institute of Chemical Engineers.

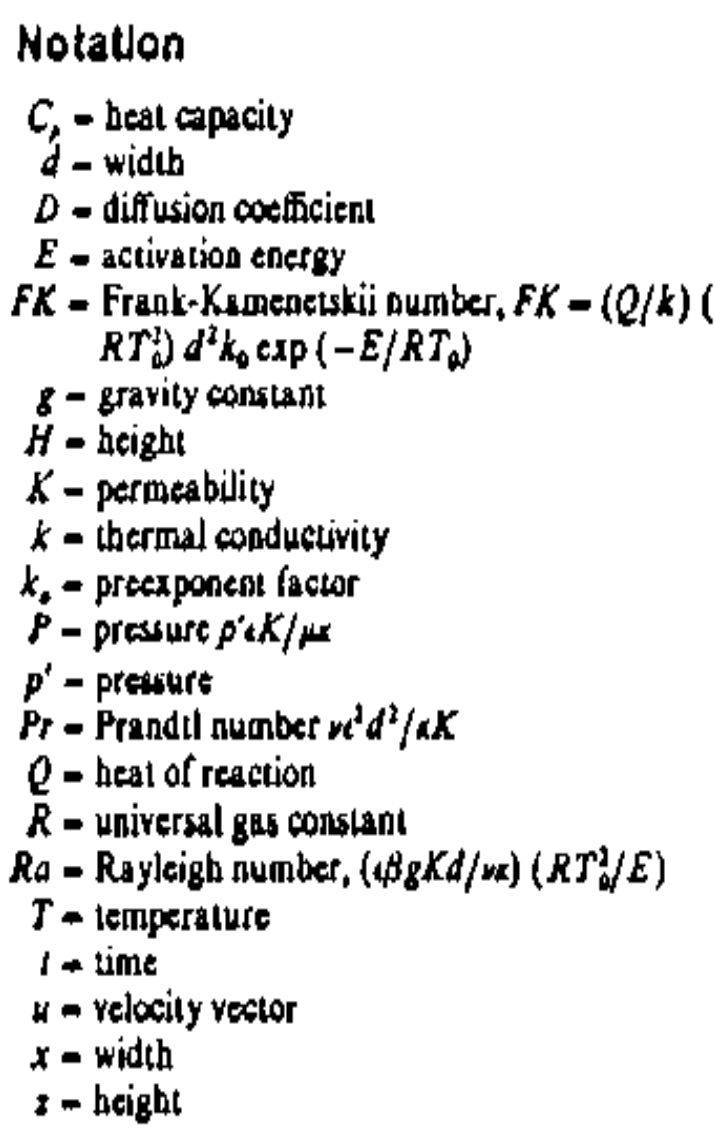

Greek letters

$$
\begin{aligned}
& a \text { = aspect ratio, widtb/height } \\
& \beta \text { - expansion coefficien }, \partial \rho / \partial T \\
& \text { i- porasity } \\
& x=\text { thetmal difusivily, } k /\left(\rho C_{j}\right)_{f} \\
& \mu=d \text { ynamic viscosily } \\
& \theta \text { - iemperalure, }\left(T-T_{0}\right) /\left(R T^{4} / E\right) \\
& p+\text { density } \\
& \nu \text { - binematic viscosily, } H / D_{J}
\end{aligned}
$$

\section{Subscripts}

$$
\begin{aligned}
& f=\text { fluid phase } \\
& o+\text { reference state }
\end{aligned}
$$

\section{Literature cited}

Buctmaster, J. D., and G. S. S. Ludford, Leciures on Mothematical Combustion, SIAM (1983).

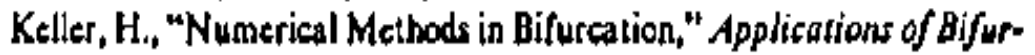
calion Theory. P. H. Rabinowilz, ed., Acadenic Press, New York (1977).

Kordylewsti, W, and Z, Krajewski, "Conwection Effects on Thermal Ignition in Porous Media," Chem. Eng. Sct, 39, 610 (1984).

Merthanov, A. O, and E. A. Shlessel, "Frec Convection and Thetmal Explosion in Redctive Systems," Acta Astronantica, 18, 19 i (1973). Shtessel, E. A, et al., "Numerical Solution of the Problem of a Thermal Explosion Tating Account of Free Convecion," J. Eng. Phys., 7, 167 (1971). 